\title{
Impact of Climate Change on Ecological Quality Indicators and Biogeochemical Fluxes in the Baltic Sea: A Multi-Model Ensemble Study
}

\author{
H. E. Markus Meier, Bärbel Müller-Karulis, Helén C. Andersson, \\ Christian Dieterich, Kari Eilola, Bo G. Gustafsson, Anders Höglund, \\ Robinson Hordoir, Ivan Kuznetsov, Thomas Neumann, Zohreh Ranjbar, \\ Oleg P. Savchuk, Semjon Schimanke
}

\begin{abstract}
Multi-model ensemble simulations using three coupled physical-biogeochemical models were performed to calculate the combined impact of projected future climate change and plausible nutrient load changes on biogeochemical cycles in the Baltic Sea. Climate projections for 1961-2099 were combined with four nutrient load scenarios ranging from a pessimistic business-as-usual to a more optimistic case following the Helsinki Commission's (HELCOM) Baltic Sea Action Plan (BSAP). The model results suggest that in a future climate, water quality, characterized by ecological quality indicators like winter nutrient, summer bottom oxygen, and annual mean phytoplankton concentrations as well as annual mean Secchi depth (water transparency), will be deteriorated compared to present conditions. In case of nutrient load reductions required by the BSAP, water quality is only slightly improved. Based on the analysis of biogeochemical fluxes, we find that in warmer and more anoxic waters, internal feedbacks could be reinforced. Increased phosphorus fluxes out of the sediments, reduced denitrification efficiency and increased nitrogen fixation may partly counteract nutrient load abatement strategies.
\end{abstract}

Keywords Baltic Sea - Numerical modeling · Climate change $\cdot$ Eutrophication $\cdot$ Scenarios .

Marine biogeochemical cycles

\section{INTRODUCTION}

\section{The Baltic Sea environment}

The Baltic Sea is a semi-enclosed sea surrounded by nine northern European countries (see Fig. S1, Electronic

Electronic supplementary material The online version of this article (doi:10.1007/s13280-012-0320-3) contains supplementary material, which is available to authorized users. supplementary material). About 85 million people live in the Baltic catchment area which is four times larger than the Baltic Sea surface area (e.g., Leppäranta and Myrberg 2009). During the past 100 years, parts of the Baltic Sea have changed from oligotrophic to eutrophic systems, caused by human-induced nutrient load increases (Elmgren 2001; Savchuk et al. 2008; Gustafsson et al. 2012). As a consequence of eutrophication, environmental problems like spreading of hypoxia and increased frequency and intensity of cyanobacteria blooms have been observed (Vahtera et al. 2007). Hypoxia increased both in the deep offshore waters (Conley et al. 2009; Savchuk 2010) and in the coastal zone (Conley et al. 2011).

\section{Baltic Sea Action Plan (BSAP)}

The Helsinki Commission's (HELCOM) BSAP aims to restore the good ecological status of the Baltic environment by 2021 (HELCOM 2007). The BSAP has the vision of "a healthy Baltic Sea, with diverse biological components functioning in balance, resulting in good ecological status and supporting a wide range of sustainable human, economic, and social activities" (HELCOM 2007). In this context, nutrient load abatement strategies have been discussed (Wulff et al. 2007). The existing BSAP was developed without taking into account possible future climate changes. However, due to the long time scales of the Baltic Sea system, observable improvements of the ecological status cannot be detected before 2040, assuming that the BSAP will be fully implemented by 2020 (Meier et al. 2011a). Thus, the impact of future climate change might be important and should be taken into account for the calculation of country-wise, maximum allowable loads of a revised BSAP. 


\section{Impact of Changing Climate}

The unprecedented warming of the Baltic Sea during the recent decades might indicate a systematically changing climate (Fonselius and Valderrama 2003). For the twentyfirst century, projections for the Baltic Sea suggest warmer waters and reduced sea-ice cover combined (eventually) with lower salinity compared to present climate (BACC 2008). These changes of the hydrography might have a significant impact on the marine ecosystem (Neumann 2010; Meier et al. 2011a, b). For instance, Meier et al. (2011a) showed that nutrient load reductions following the BSAP combined with A1B greenhouse gas emissions (Nakićenović et al. 2000) would result in only slightly smaller hypoxic areas compared to present climate. To produce these results Meier et al. (2011a) used regionalized climate data sets from global scenario simulations using General Circulation Models (GCMs) of the latest assessment report of the Intergovernmental Panel on Climate Change (IPCC) (Solomon et al. 2007). In this study, the multi-model ensemble approach of scenario simulations used by Meier et al. (2011a) is further developed.

\section{New Method}

An ensemble of simulations for the period 1961-2099 was performed with coupled physical-biogeochemical models, driven with regionalized climate data to calculate the impact of nutrient load reductions in a future climate. Uncertainties in the model simulations are caused by biases of global and regional climate models (RCM) and coupled physical-biogeochemical models of the Baltic Sea as well as by unknown socioeconomic developments with impacts on greenhouse gas emissions and nutrient loadings from land. The ensemble simulations allow the calculation of the ensemble mean and the standard deviation among the ensemble members to quantify the spread within the ensemble, henceforth considered as a measure of uncertainty. Thus, it is assumed that the models are independent of each other. New for the approach of this study compared to earlier efforts, e.g., by Meier et al. (2011b) and Neumann (2010), is that the model ensemble comprises even three different marine biogeochemical and two catchment models to assess uncertainties of biogeochemical process descriptions and of runoff and nutrient loads, respectively.

\section{Aim}

The aim of this study is to calculate changing water quality in a future climate, assuming plausible nutrient load scenarios and to explain the causes of climate effects by analyzing biogeochemical fluxes between nutrient pools, simulated with the Baltic Sea models.

\section{MATERIALS AND METHODS}

\section{Dynamical Downscaling Approach}

As the horizontal resolution of GCMs is too coarse to resolve regional details, a RCM with increased resolution is used which enables a greater number of explicitly resolved processes and a better representation of surface conditions like the regional orography and land-sea mask. In the dynamical downscaling approach, the RCM is driven at the lateral boundaries of the model domain by GCM data. Thus, the large-scale circulation is controlled by the GCM dynamics, whereas the RCM adds regional details. The more realistic atmospheric surface fields of the RCM are used to force three coupled physical-biogeochemical models for the Baltic Sea.

\section{Global Climate Models}

In this study, lateral boundary data from two GCMs are used: HadCM3 from the Hadley Centre in the UK (Gordon et al. 2000) and ECHAM5/MPI-OM from the Max Planck Institute for Meteorology in Germany (Jungclaus et al. 2006; Roeckner et al. 2006), henceforth short ECHAM5. HadCM3 is forced with the A1B greenhouse gas emission scenario (Nakićenović et al. 2000), whereas ECHAM5 is driven both with A1B and A2. These scenarios were selected because projected global mean surface temperature changes are at medium scale within the range of available IPCC scenarios (Solomon et al. 2007). In this study, the uncertainty due to unknown future greenhouse gas emissions is not addressed.

As in both ECHAM5 scenario simulations the projected increases of global mean surface temperature are quite similar, they are considered together within one ensemble. In addition, two realizations of ECHAM5 forced with A1B greenhouse gas emissions, but using differing initial conditions, are studied (denoted with -r1 and -r3). Hence, in total four GCM datasets, HadCM3-A1B, ECHAM5-r3A1B, ECHAM5-r1-A1B, and ECHAM5-r1-A2, are used. All simulations are transient runs for the period 1961-2099.

\section{Regional Climate Model}

The results of the four global scenario simulations are downscaled using the coupled atmosphere-ice-ocean model RCAO (Rossby Centre Atmosphere Ocean model, see Döscher et al. 2002) with a horizontal resolution of $25 \mathrm{~km}$ (Meier et al. 2011c). RCAO model results in the form of three-hourly atmospheric surface fields like 2-m air temperature, 2-m specific humidity, sea level pressure, $10-\mathrm{m}$ wind speed, precipitation, and total cloudiness are 
used to force three Baltic Sea models and two hydrological models.

For the control period (CTL, defined as 1978-2007), the quality of the atmospheric surface fields calculated with RCAO was assessed by Meier et al. (2011c). ECHAM5 and HadCM3 were selected because biases of RCAO driven by these GCMs over the Baltic Sea region are relatively small compared to biases of other GCMs (Meier et al. 2011c). According to Meier et al. (2011c), in ECHAM5-driven simulations, the winter mean air temperature especially in the northern Baltic Sea is generally too warm. Otherwise, the results are satisfactory.

In the Baltic Sea region, the four investigated projections suggest that the annual mean temperature and precipitation will increase between 2.7 and $3.8^{\circ} \mathrm{C}$, and between 12 and $18 \%$, respectively (Meier et al. 2012).

\section{Hydrological Models}

Runoff is calculated with two different methods. First, a statistical model (STAT) is used to calculate the runoff into five different sub-basins, i.e., Bothnian Bay, Bothnian Sea, Gulf of Finland, Baltic proper, and Kattegat from the difference of precipitation and evaporation from RCAO over land (Meier et al. 2012). Second, the more sophisticated process oriented, hydrological model HYdrological Predictions for the Environment (HYPE, see Arheimer et al. 2012), driven with precipitation and air temperature fields from RCAO is used to calculate the water discharge of the 29 largest rivers (even including not gauged coastal segments) for 1961-2099 (Arheimer et al. 2012). Hence, HYPE resolves the regional scales of the Baltic catchment area in more detail than STAT.

\section{Baltic Sea Models}

The transient simulations for 1961-2099 were carried out with three state-of-the-art, coupled physical-biogeochemical models. These are the BAltic sea Long-Term largeScale Eutrophication Model (BALTSEM) (Savchuk 2002; Gustafsson 2003), the Ecological Regional Ocean Model (ERGOM) (Neumann et al. 2002), and the Swedish Coastal and Ocean Biogeochemical model coupled to the Rossby Centre Ocean circulation model (RCO-SCOBI) (Meier et al. 2003; Eilola et al. 2009). The models are structurally different in that ERGOM and RCO-SCOBI are threedimensional circulation models with uniformly high horizontal resolution of 5.6 and $3.7 \mathrm{~km}$, respectively, while BALTSEM resolves the Baltic Sea spatially in 13 dynamically interconnected and horizontally integrated sub-basins with high vertical resolution. All models are forced with the same three-hourly atmospheric and monthly river runoff data from four climate projections (see above). The time steps of RCO-SCOBI, ERGOM, and BALTSEM amount to $150 \mathrm{~s}, 600 \mathrm{~s}$ and $3 \mathrm{~h}$, respectively.

A thorough comparison of hindcast simulation results of the three biogeochemical models driven with regionalized ERA-40 re-analysis data (Samuelsson et al. 2011) during 1970-2005 was performed by Eilola et al. (2011). Eilola et al. (2011) concluded that the models capture much of the observed variability and that during 1970-2005, the response to changing physical conditions is simulated realistically.

\section{Nutrient Load Scenarios}

Nutrient loads from rivers are calculated from the products of riverine nutrient concentrations and water discharges following, e.g., Stålnacke et al. (1999). The approach was successfully used earlier by Eilola et al. (2009) and Meier et al. (2011b). Four scenarios are considered:

- REFerence (REF): current riverine nutrient concentrations and current atmospheric deposition (see Eilola et al. 2009),

- Current LEGislation (CLEG): riverine nutrient concentrations according to the legislation on sewage water treatment (EU wastewater directive) and $25 \%$ reduction of atmospheric nitrogen deposition,

- BSAP: reduced riverine nutrient concentrations following HELCOM (2007) and 50\% reduction of atmospheric deposition,

- Business-As-Usual (BAU): increased nutrient concentrations in rivers assuming an exponential growth of agriculture in all Baltic Sea countries as projected in HELCOM (2007) and current atmospheric deposition.

Between 2007 and 2020, simulated nutrient concentrations in rivers, loads from point sources, and atmospheric deposition change linearly from present to future values. After 2020, nutrient concentrations are assumed to be constant. The nutrient load scenarios are implemented in the Baltic Sea models as relative changes compared to the loads for the control period because the nutrient loads differ among the models. The major differences are due to the different assumptions on the bioavailability of phosphorus loads (Eilola et al. 2011).

\section{Boundary Conditions in Kattegat/Skagerrak}

All three models have an open boundary in the northern Kattegat (BALTSEM, RCO-SCOBI) or in the Skagerrak (ERGOM). At the boundaries, vertical profiles of temperature, salinity, and nutrients (inorganic and organic) are relaxed to climatological mean observations of the control period in a model specific manner. In the scenario simulations, these boundary conditions do not change with time. 
As inflow water into the Baltic Sea originates from the surface layer in Kattegat, we assume that changing boundary conditions will not affect the results of the scenario simulations much within the Baltic Sea. However, results for the Kattegat and Skagerrak are less reliable.

Sea levels at the open boundaries are calculated with the help of statistical models from the meridional atmospheric pressure difference across the North Sea following Gustafsson and Andersson (2001). In case of RCO-SCOBI and BALTSEM, a statistical method is applied to correct underestimated sea level extremes (Meier et al. 2012).

\section{Initial Conditions}

The Baltic Sea models are started from initial conditions representing the beginning of the 1960s, following Eilola et al. (2011). Due to model-specific spin-up periods, these initial conditions differ among the models. However, in all scenario simulations, the same initial conditions for each model are used.

\section{Analysis Strategy}

We focus the analysis on changing ecological quality indicators like winter surface nutrient, summer bottom oxygen, and annual mean phytoplankton concentrations, as well as annual mean Secchi depths between present (1978-2007) and future (2069-2098) climates. Surface concentrations are vertically averaged over the upper $10 \mathrm{~m}$. Secchi depth $(\mathrm{Sd})$ is calculated from $\mathrm{Sd}=1.7 / k(\mathrm{PAR})$, where $k(\mathrm{PAR})$ is the coefficient of underwater attenuation of the photosynthetically available radiation (e.g., Kratzer et al. 2003). Factors controlling $k(\mathrm{PAR})$ in our models are the concentrations of phytoplankton and detritus. In addition, salinity is used in BALTSEM as a proxy of the spatiotemporal dynamics of yellow substances.

Ensemble means and standard deviations among the ensemble members are calculated. Ensemble mean changes with a signal-to-noise ratio (the ratio between the absolute value of the ensemble mean change and the standard deviation) smaller than one are regarded as not significant. In total, 16 scenario simulations for 1961-2098 were performed both with RCO-SCOBI and BALTSEM using runoff from STAT (see Table S1, Electronic supplementary material). With ERGOM, only six transient experiments were carried out. As ERGOM and climate projections based upon HadCM3 are under-represented in our ensemble compared to the other two Baltic Sea models and compared to ECHAM5-driven simulations, the ensemble members were weighted according to Table S1 (Electronic supplementary material). However, our analysis indicates that the overall conclusions of this study do not depend on the chosen weights (not shown).
To follow the changes in nitrogen and phosphorus turnover, biogeochemical fluxes were extracted from a subset of the ensemble for the entire Baltic Sea, excluding the Kattegat. These runs with the three Baltic Sea models were driven by HadCM3-A1B and ECHAM5-r3-A1B realizations with nutrient inputs according to the REF, BSAP, and BAU scenarios generated from STAT (or HYPE in case of RCO-SCOBI) river runoff. We calculated the total $\mathrm{N}$ and $\mathrm{P}$ supply to the water column from the sum of nutrient release from the bottom sediments, input by nitrogen fixation, and by land and atmospheric loads, minus the net export of bioavailable nutrients to the Kattegat. As the net export term was not directly available from all the models, we determined it by a simple mass balance:

$E-I=L-B+N-D-\Delta T$ pel $-\Delta T$ sed,

where $E-I$ denotes the net nutrient export to the Kattegat, $L$ is the load from land and atmosphere, $B$ is the nutrient removal by burial in the bottom sediments, $N$ is the nitrogen input from nitrogen fixation, $D$ is the removal by denitrification, and $\Delta T$ pel and $\Delta T$ sed are the changes in nutrient pools in the water column and bottom sediments, respectively. Both the pelagic and the sediment pools consist of total inorganic and bioavailable organic nitrogen or phosphorus.

\section{Cause-and-Effect Studies}

In addition to the large ensemble consisting of 38 simulations using RCO-SCOBI, BALTSEM, and ERGOM forced with runoff from STAT (Table S1, Electronic supplementary material), also 16 scenario simulations using RCOSCOBI forced with HYPE were carried out. The latter simulations are not considered for the calculation of the ensemble mean changes as mentioned above but are used to compare the effect of differing runoff forcing data sets on RCO-SCOBI results.

\section{RESULTS}

\section{Evaluation of the Control Period}

Results from control simulations, i.e., model results forced with regionalized GCM data in the present climate, are evaluated. 30-year-long records of model results are compared with observations from 1978 to 2007. Note that GCM-driven simulations cannot reproduce the observed chronology due to the chaotic nature of the Earth system and, for instance, the observed stagnation period 1983-1993 may not be reflected in the model results. In principle, GCM-driven simulations will only reproduce the statistics of observed weather, i.e., observed climate, if the models are perfect. We compare the simulated ensemble 
mean and observed mean vertical profiles of water temperature, salinity, oxygen, phosphate, nitrate, and ammonium concentrations at two selected stations (for the locations see Fig. S1, Electronic supplementary material), Gotland Deep (BY15) with a permanent halocline and LL07 in the Gulf of Finland. At LL07, the stratification is weaker and the bottom layer is intermittently ventilated due to wind-driven mixing events.

Simulated ensemble mean temperature and salinity profiles are in accordance with observations and in general within the range of $\pm 1 \mathrm{SD}$ from the observed mean profiles (Fig. 1a-d). However, the halocline in the Baltic proper is too shallow (especially in HadCM3-driven simulations, not shown) and the vertical stratification in the Gulf of Finland is too strong. Oxygen and nutrient concentrations are simulated satisfactorily (Fig. 1e-1), although (very likely) the bias of the vertical stratification in the Gulf of Finland causes too low oxygen and too high phosphate concentrations in the bottom water. In the Arkona, Bornholm, and Gotland basins, nutrient dynamics are generally better simulated than in the northern Baltic Sea (not shown), in agreement with results by Eilola et al. (2011).

\section{Changing Runoff and Nutrient Loads}

Despite rather different approaches in STAT and HYPE, the results are qualitatively similar. According to STAT and
HYPE, the projected total runoff into the Baltic Sea (without Kattegat) increases between 15 and $22 \%$ and 4 and $13 \%$, respectively (Fig. 2). A common spatial signal is that the largest increase occurs in the northern Baltic Sea during winter. This result is in agreement with earlier findings by Graham (2004), who used a large-scale basin-wide hydrological model for the Baltic catchment. In one out of four HYPE projections, the runoff into the Baltic proper and the Gulf of Riga even decreases (Fig. 2). However, scenario simulations with HYPE are perhaps more realistic than the corresponding calculations with STAT because precipitation fields from the RCM used as forcing in HYPE are bias corrected (Arheimer et al. 2012). In addition, the calculation of evaporation from surface temperatures in HYPE takes more detailed information about land surface conditions into account than in state-of-the-art RCMs. Also, the spatial resolution in HYPE is much higher than in STAT which suggests that the spatial distribution of calculated runoff changes is more realistic.

In Fig. 3, the ensemble mean changes of total bioavailable phosphorus and nitrogen loads comprising the loads from rivers, point sources, and atmospheric deposition between future and present climates are shown. Note that climate change induced nutrient concentration changes in rivers are not considered. For instance, riverine nitrogen concentrations may decrease because of increased denitrification in warmer soils and phosphorus concentrations may increase because of more frequent, heavy rainfall
Fig. 1 Ensemble average vertical profiles and changes in a-b temperature (in ${ }^{\circ} \mathrm{C}$ ), c-d salinity $\left(\mathrm{g} \mathrm{kg}^{-1}\right)$ and e, $\mathbf{f}$ oxygen (in $\mathrm{ml} \mathrm{O}_{2} \mathrm{l}^{-1}$ ), $\mathbf{g}, \mathbf{h}$ phosphate (in mmol $\mathrm{P} \mathrm{m}^{-3}$ ), $\mathbf{i}, \mathbf{j}$ nitrate (in $\mathrm{mmol} \mathrm{N} \mathrm{m}{ }^{-3}$ ) and $\mathbf{k}, \mathbf{l}$ ammonium (in $\mathrm{mmol} \mathrm{N} \mathrm{m}^{-3}$ ) concentrations at the monitoring stations at Gotland Deep (BY15, left panels) and in the Gulf of Finland (LL07, right panels) (for locations see Fig. S1, Electronic supplementary material): observations (green), control period 1978-2007 (black), changes between 2069-2098 and 1978-2007 in BSAP (blue), CLEG (cyan), REF (black), and BAU (red). Negative oxygen values represent hydrogen sulfide. The range of variability is indicated by the \pm 1 standard deviation band around the ensemble average of model results (dotted lines) or observations (gray shaded area)
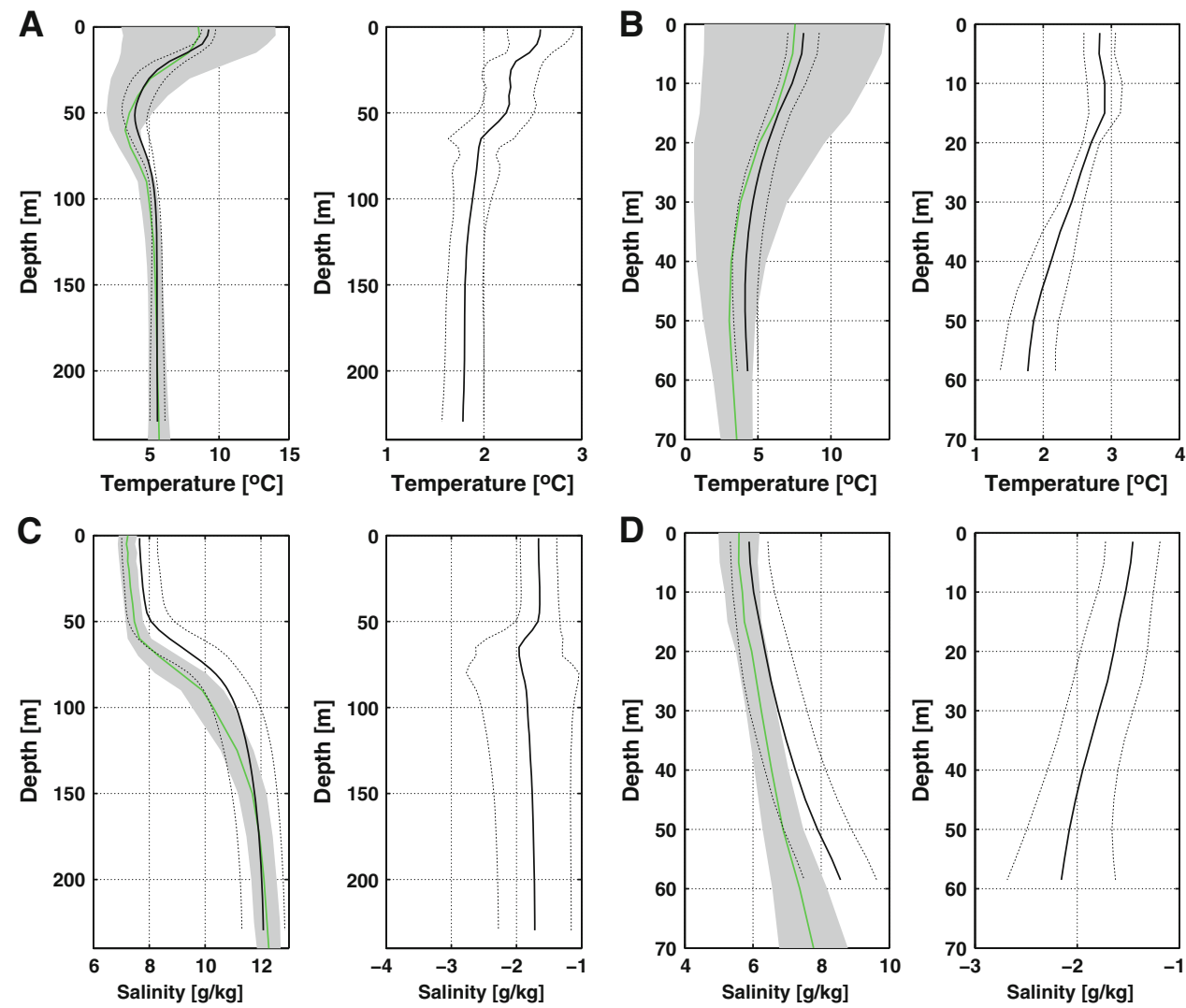

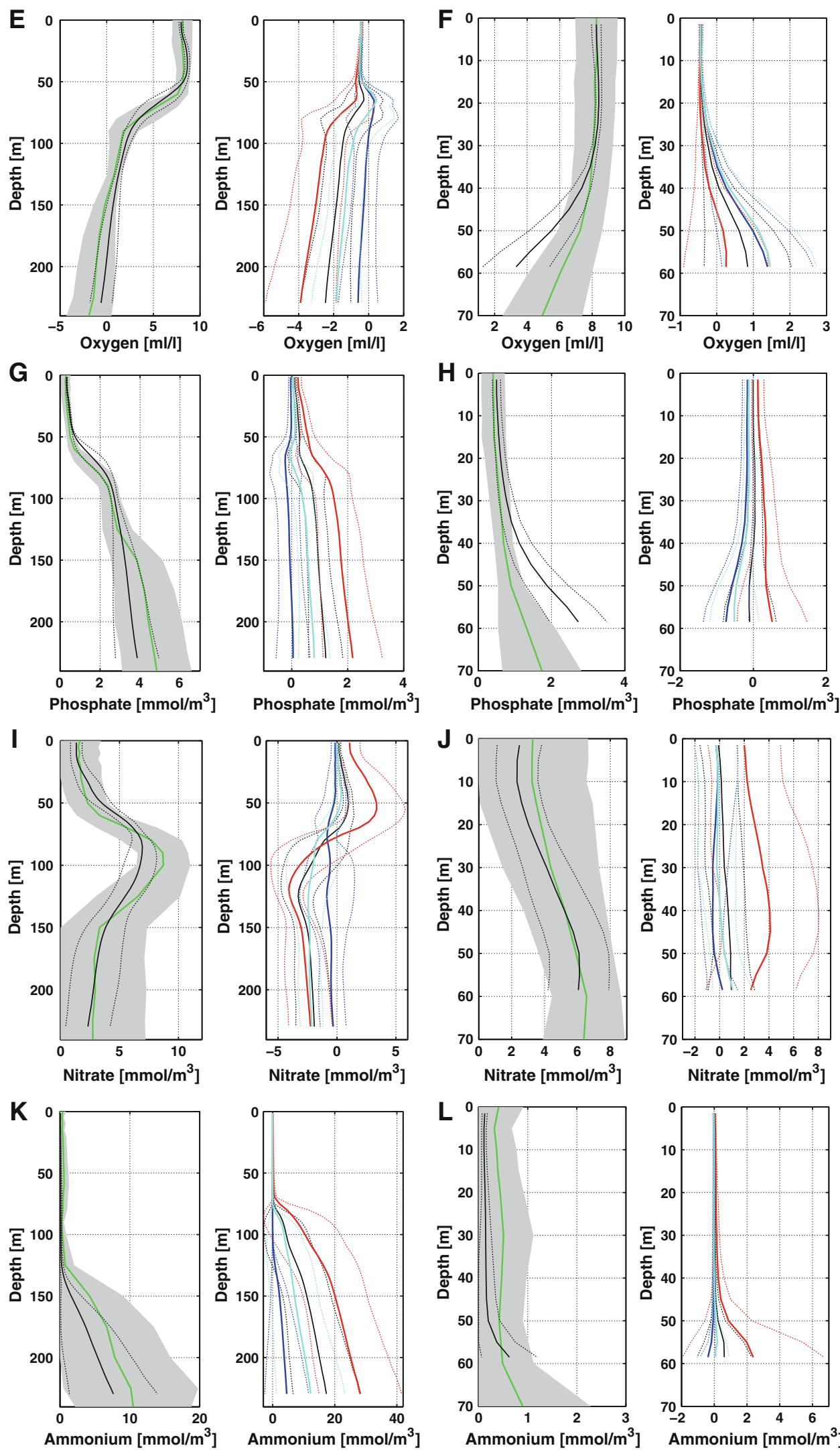

Fig. 1 continued

Ammonium $\left[\mathrm{mmol} / \mathrm{m}^{3}\right.$ ] 
Fig. 2 River runoff changes (in $\%$ ) between 1971-2000 and 2070-2099, simulated with two different hydrological models (STAT and HYPE), each driven with four climate simulations (ECHAM5-r3-A1B = E5A1B3, ECHAM5-r1-A1B = E5A1B1, ECHAM5-r1-A2 = E5A2, HadCM3-A1B = HADA1B). The river runoff into the Bothnian Bay (BB), Bothnian Sea (BS), Gulf of Finland (GF), Gulf of Riga (GR), Baltic proper (BP), total Baltic Sea (excluding Kattegat) (TOT) and Kattegat (KA) is depicted

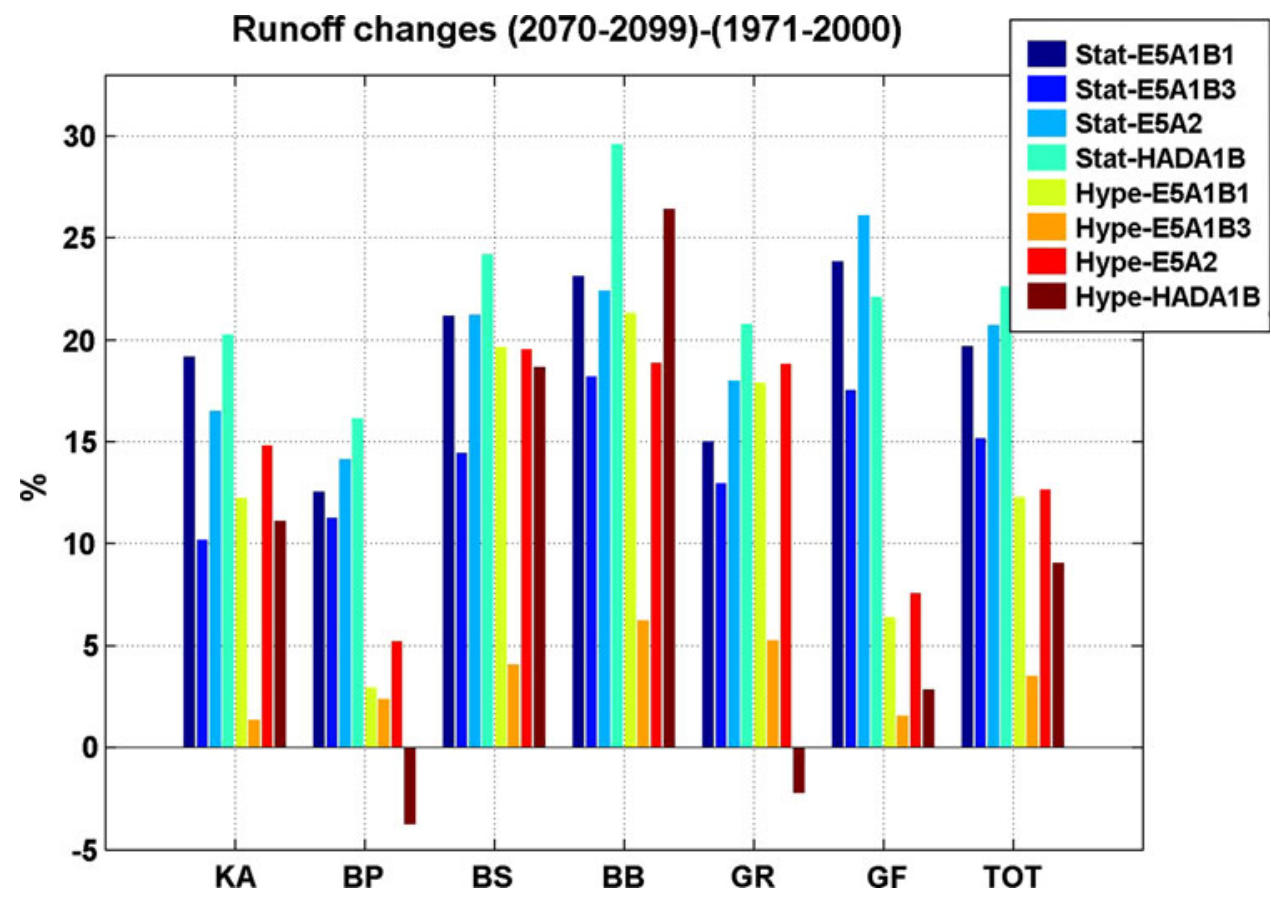

which may flush phosphorus out of the soils (Arheimer et al. 2012). However, as these processes are not well understood, climate change induced nutrient concentration changes remain rather uncertain. Hence, we assume that, for a given nutrient load scenario, nutrient concentrations are constant in time, following earlier approaches (e.g., Stålnacke et al. 1999). Consequently, the increase of total bioavailable phosphorus and nitrogen loads in future climate is accelerated in BAU due to the projected increase of freshwater runoff (Fig. 3a, b). Also, the nutrient load reductions in BSAP are affected and less efficient in the wetter future than in present climate.

\section{Changing Water Temperature}

The largest sea surface temperature (SST) changes occur during summer in the northern Baltic Sea (Fig. S2a, Electronic supplementary material). We found ensemble mean changes of more than $4{ }^{\circ} \mathrm{C}$ in the Bothnian Bay and of about $2.5^{\circ} \mathrm{C}$ in large areas of the Baltic proper (Bornholm Basin, Gotland Basin) and the Gulf of Riga. The northern amplification of the warming is partly explained by the ice-albedo feedback due to the larger sensitivity of SSTs in seasonal ice covered sea areas as climate is warming (Meier et al. 2011c). The water temperature in the surface layer increases by about $1{ }^{\circ} \mathrm{C}$ more than in the deep layer (Fig. 1a, b).

\section{Changing Salinity}

Due to the increased freshwater supply, sea surface and bottom salinities are projected to decrease (Fig. S2b, c,
Electronic supplementary material). In the Baltic proper, the vertical distributions of salinity changes are rather homogeneous (Fig. 1c). Ensemble mean salinities are projected to decrease by about $1.5-2 \mathrm{~g} \mathrm{~kg}^{-1}$. The changes are slightly larger in the bottom water of the deep subbasins and in the Gulf of Finland (Fig. 1d). Hence, the density difference between bottom and surface waters slightly decreases. At Gotland Deep, the largest changes are found in the depth range of the halocline due to a deepening of the halocline (Fig. 1c). However, these changes in halocline depth are rather uncertain because simulated changes in BALTSEM are larger than in ERGOM and RCO-SCOBI (not shown). As the habitat of many marine species is influenced by the salt conditions, the projected salinity decrease may affect the biodiversity of the marine ecosystem considerably.

\section{Changing Pelagic and Sediment Nutrient Pools}

Relative changes of pelagic and sediment nutrient pools are largest in BAU (Fig. 3). In BSAP, ensemble mean nutrient pools decrease both in the water and the sediment, but also in this case, some simulations show increased pools (Fig. 3).

\section{Changing Summer Bottom Oxygen Concentration}

Summer bottom oxygen concentrations are generally projected to decrease in almost all regions (Fig. S2d-g, Electronic supplementary material). Also with reduced nutrient loads in BSAP and CLEG, significantly increased 
Fig. 3 Ensemble average changes of the annual mean biologically available total phosphorus (a) and nitrogen (b) loads from rivers, point sources and atmospheric deposition and of the sediment and pelagic pools (in \%). The changes for the total Baltic Sea (including Kattegat) are calculated between 1971-2000 and 2070-2099. In addition, the \pm 1 standard deviation bands around the ensemble average changes are shown
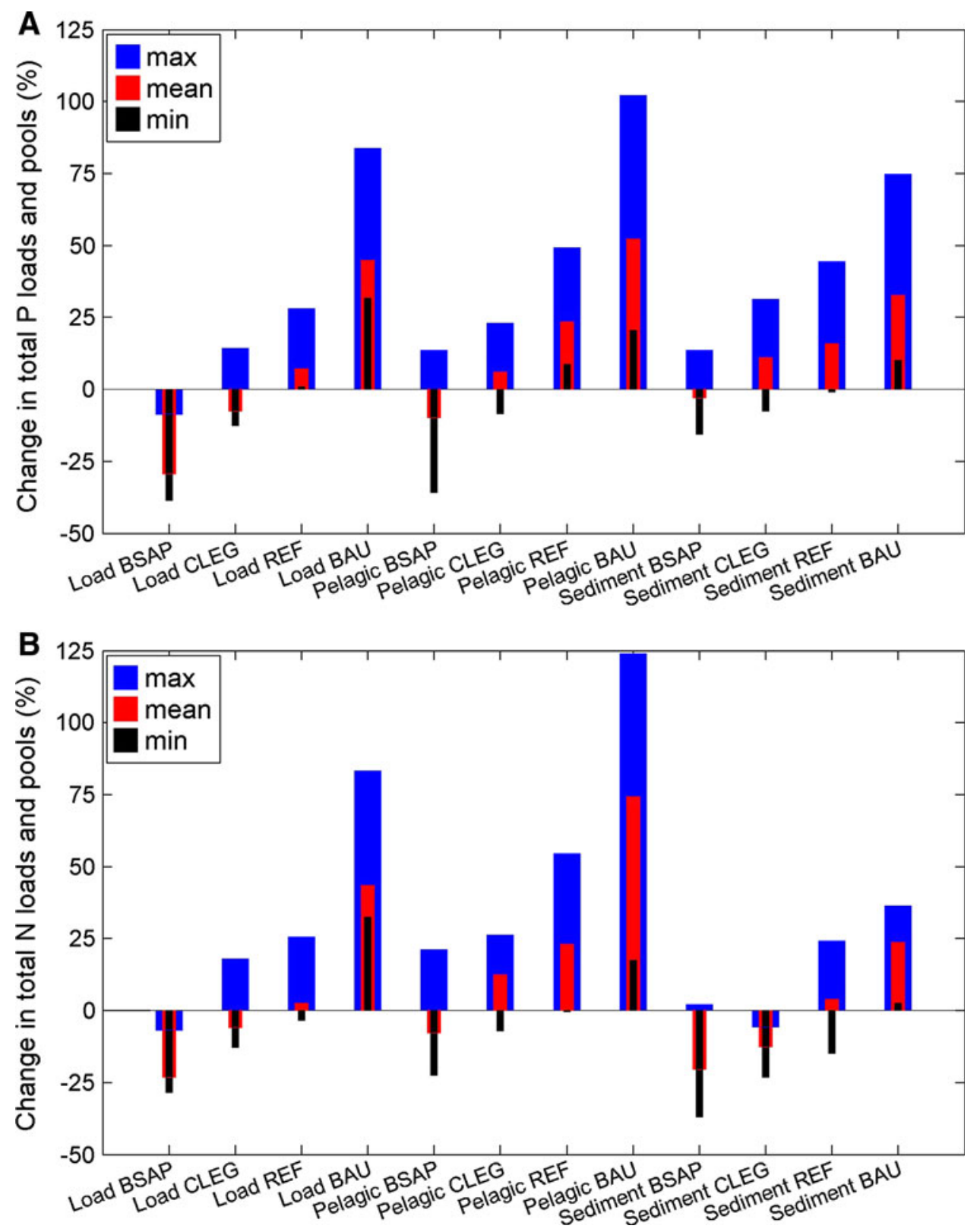

bottom oxygen concentrations are found only in the central Gulf of Finland (Fig. S2d-e, Electronic supplementary material). These improved oxygen conditions are partly caused by a weaker vertical stratification (Fig. 1d), which enables reinforced ventilation of the bottom layer.

As the solubility of atmospheric oxygen decreases in warmer water, oxygen concentrations in the surface layers and consequently also in the bottom waters in weakly stratified coastal areas are reduced in all scenarios. In CLEG, REF, and BAU, the oxygen decrease in the deep water of the Baltic proper is even larger than in bottom waters of the coastal zone (largest in BAU and smallest in CLEG) (Fig. S2e-g, Electronic supplementary material). In BSAP, bottom oxygen concentrations also decrease in the
Gotland Deep area but increase in the depth range of the halocline (not shown). However, these changes in BSAP are smaller than the spread within the ensemble and consequently not depicted in Fig. S2d (Electronic supplementary material). In the depth range of the halocline and in the deep water of the Bothnian Bay and Bothnian Sea, projected bottom oxygen concentration changes are relatively uncertain in all nutrient load scenarios.

\section{Changing Winter Surface Nutrient Concentration}

Projected winter surface nutrient concentration changes vary substantially among the models (Fig. S2h-o, Electronic supplementary material). However, a common 

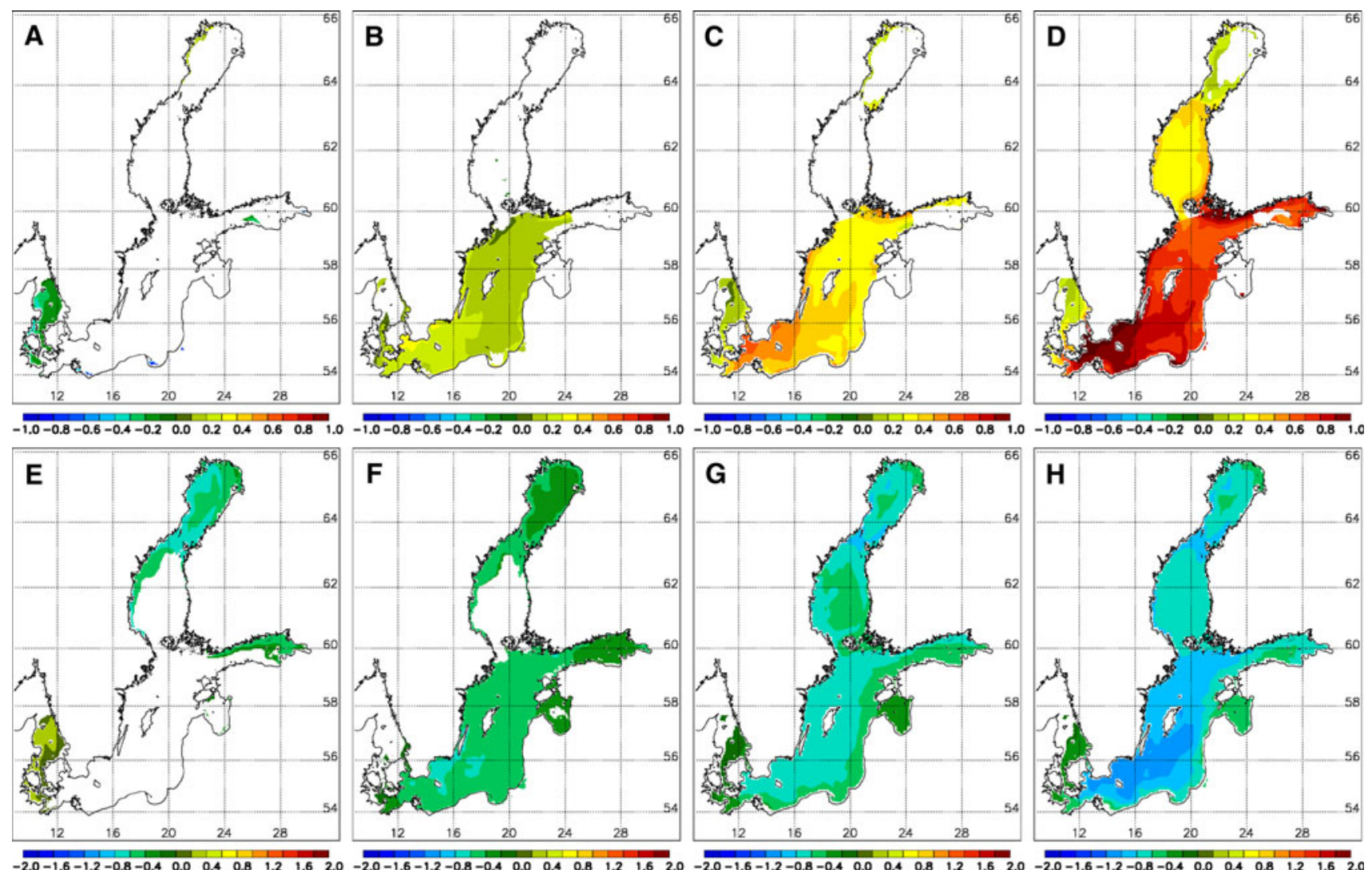

Fig. 4 Ensemble mean changes between 2069-2098 and 1978-2007 of a-d annual mean phytoplankton concentration (in $\mathrm{mg} \mathrm{Chl} \mathrm{m}^{-3}$ ) and $\mathbf{e}-\mathbf{h}$ Secchi depth (in $\mathrm{m}$ ). From left to right, the nutrient load scenarios BSAP, CLEG, REF, and BAU are shown. Areas with a

behavior is that with increasing nutrient supply, surface concentrations of both dissolved inorganic phosphorus (DIP) and dissolved inorganic nitrogen (DIN) increase. In the Baltic proper, winter DIN significantly increases in REF and BAU and winter DIP increases in CLEG, REF, and BAU. Largest changes in DIN are found in BAU in the eastern Gulf of Finland and in the Gulf of Riga (Fig. S2o, Electronic supplementary material). In BSAP, simulated winter surface nutrient concentration changes differ between the models, and ensemble mean changes are not significant (Fig. S2h, 1, Electronic supplementary material). An exception is the eastern Gulf of Finland area with significantly reduced DIP concentrations.

In the deep water of the central Baltic proper, phosphate and ammonium concentrations increase and nitrate concentrations decrease with increasing nutrient loads (Fig. 1g-1). These changes are caused by decreasing oxygen concentrations (Fig. 1e-f). In BSAP, phosphate, nitrate, and ammonium concentration changes are relatively small. In the deep water of the Gulf of Finland, both the DIP and the DIN concentrations increase in BAU and decrease in BSAP. signal-to-noise ratio smaller than one, i.e., the absolute value of the ensemble average change is smaller than the standard deviation of the individual changes, are shown in white

\section{Changing Phytoplankton Concentration and Secchi Depth}

In almost all areas of the Baltic proper and in all nutrient load scenarios, spring phytoplankton concentration changes are not significant (not shown). However, in REF and BAU summer cyanobacteria concentrations in the Arkona and Bornholm basins are projected to increase significantly (not shown). Hence, in these scenarios and also in CLEG, annual mean phytoplankton concentrations increase (Fig. 4a-d). Consequently, the Secchi depth decreases (Fig. 4e-h).

\section{Cause-and-Effect Studies}

Although the magnitude of changes in ecological quality indicators is larger in STAT than in HYPE-driven simulations (cases REF and BAU), the changes in all scenarios agree qualitatively (not shown). Hence, the cause-andeffect analysis of changing processes and biogeochemical fluxes does not depend on the choice of the hydrological model. 


\section{Changing Biogeochemical Fluxes and Nutrient Budgets}

Despite only minor changes in phosphorus and nitrogen loads in the REF scenario, the model ensemble projects a substantial $(60 \%)$ increase in primary production (Fig. 5a). In the BAU scenario, primary production roughly doubles, while the BSAP reduces primary production slightly. The uncertainty in the ensemble, described by the ensemble standard deviation, increases with increased nutrient loads from BSAP, to REF and BAU scenarios. In contrast to primary production, nitrogen fixation shows little difference between the REF and BAU scenarios, which both approximately triple the influx of fixed dinitrogen (Fig. 5b). BSAP implementation would only stabilize nitrogen fixation on a high level of twice the flux in 1971-2000. Ensemble means, in particular for BSAP scenarios, show a transition period after the load changes in 2007, when nitrogen fixation rates initially increase, contrary to their later long-term decreasing behavior.

Compared to primary production and nitrogen fixation, the rates of sediment processes show less change, which is projected with more certainty. Both the phosphorus (Fig. 5c) and the nitrogen (Fig. 5d) release from the bottom sediments are projected to increase in REF and BAU scenarios, whereas the BSAP would result in a decline after 2007. Due to increased phosphorus mobility in the sediments (Fig. 5f), the relative changes in phosphorus outflux from the bottom sediments are larger than the changes in the sediment phosphorus pool in all cases (Fig. 5e). As the sediment pools show no significant trends during the last 20-30 years of the simulations, we do not expect any drastic changes after 2099. Higher temperatures accelerate phosphorus mineralization in the bottom sediments, and low oxygen concentrations further increase the phosphorus release to the water column. Therefore, the increase in phosphorus mobility is largest in the highly anoxic BAU scenario and weakest in the BSAP scenario.

The different load scenarios also have a pronounced effect on denitrification, the major nitrogen sink in the Baltic Sea. Denitrification was simulated to increase by 30 and $50 \%$ in REF and BAU scenarios, respectively, and to decline slightly with BSAP nutrient loads (Fig. 5g). However, the denitrification increase in the BAU scenario is smaller than the enhanced nitrogen output from the bottom sediments. Hence, denitrification becomes less efficient and removes a smaller fraction of the total nitrogen supply (Fig. 5h). In the BAU scenario, anoxia may significantly weaken the efficiency of the Baltic Sea denitrification sink. Denitrification efficiency remains approximately the same in the REF scenario and slightly improves with BSAP nutrient loads.
The changing nutrient fluxes from the bottom sediments, together with changes in nitrogen fixation and denitrification, have a pronounced effect on the nutrient supply to the water column in future climate (Fig. 6), which is calculated here as the sum of nutrient release from the bottom sediments, input by nitrogen fixation, and by land and atmospheric loads minus the net export of bioavailable nutrients to the Kattegat. Present (1978-2007) and future (2069-2097) phosphorus release from the bottom sediments is $4.5-6$ times larger than the bioavailable loads from land and atmosphere (Table 1). Thus, the release from the bottom sediments provides $84-89 \%$ of the annual phosphorus supply to the water column. Nitrogen is contributed in similar portions by bottom sediments, nitrogen fixation, and land and atmospheric loads. Compared to the control period, the total phosphorus fluxes into the water column increase by 12 and $35 \%$ until 2069-2097 in the REF and BAU scenarios, respectively, while the BSAP scenario reduces the total phosphorus supply by $12 \%$. The effect of the BSAP on the total nitrogen supply to the Baltic Sea ecosystem is even smaller $(-4 \%)$, as increasing nitrogen fixation almost offsets the decreased nitrogen load. However, the nitrogen turnover becomes much larger in REF and BAU scenarios. Sediment release and nitrogen fixation raise the total nitrogen supply by $27 \%$ in the REF scenario, despite almost constant loads, and the increase is even larger in the BAU scenario (55\%).

\section{Phytoplankton Growth}

Primary production follows the trends in the phosphorus supply to the water column in all models and scenarios (Fig. 7, top left). However, nutrients can be used for phytoplankton production several times before they reach the bottom sediments due to pelagic decomposition (i.e., bacterial detritus mineralization and zooplankton excretion) and vertical transports of the mineralized nutrients to the productive surface layer. Therefore, primary production is always larger than the Redfield equivalent of the nutrient supply from bottom sediments and land loads (the Redfield ratio is the molecular ratio of carbon, nitrogen and phosphorus in plankton). The intensity of the pelagic recycling loop is model specific and models with stronger recycling simulate larger primary production.

Phytoplankton growth also responds to changes in the input of nitrogen from bottom sediments and external loads (Fig. 7, top right). However, the relationship is somewhat weaker compared to the relationship between primary production and phosphorus supply. Thus, in addition to the supply from loads and sediments, nitrogen fixation fuels primary production when phosphorus is available. Nitrogen and phosphorus supply from bottom sediments and external 
Fig. 5 Ensemble average relative changes (solid lines) of selected biogeochemical fluxes and pools in REF (black), BSAP (blue) and BAU (red) scenarios. Panels show primary production (a), nitrogen fixation (b), phosphorus (c), and nitrogen (d) release from bottom sediments, the sediment phosphorus pool (e), ratio between phosphorus release and sediment phosphorus pool (f), denitrification $(\mathbf{g})$, and the ratio between denitrification and the nitrogen supply from bottom sediments, nitrogen fixation, and net input from loads and exchange with the Kattegat (h). The range of variability is indicated by the \pm 1 standard deviation band around the ensemble average (dotted lines) of results from six experiments, based upon two climate projections (HadCM3-A1B and ECHAM5-r3-A1B) and three Baltic Sea models (RCOSCOBI, BALTSEM, ERGOM), see "Materials and methods" section. Fluxes are shown as decadal moving averages (11 years) relative to 1971-2000
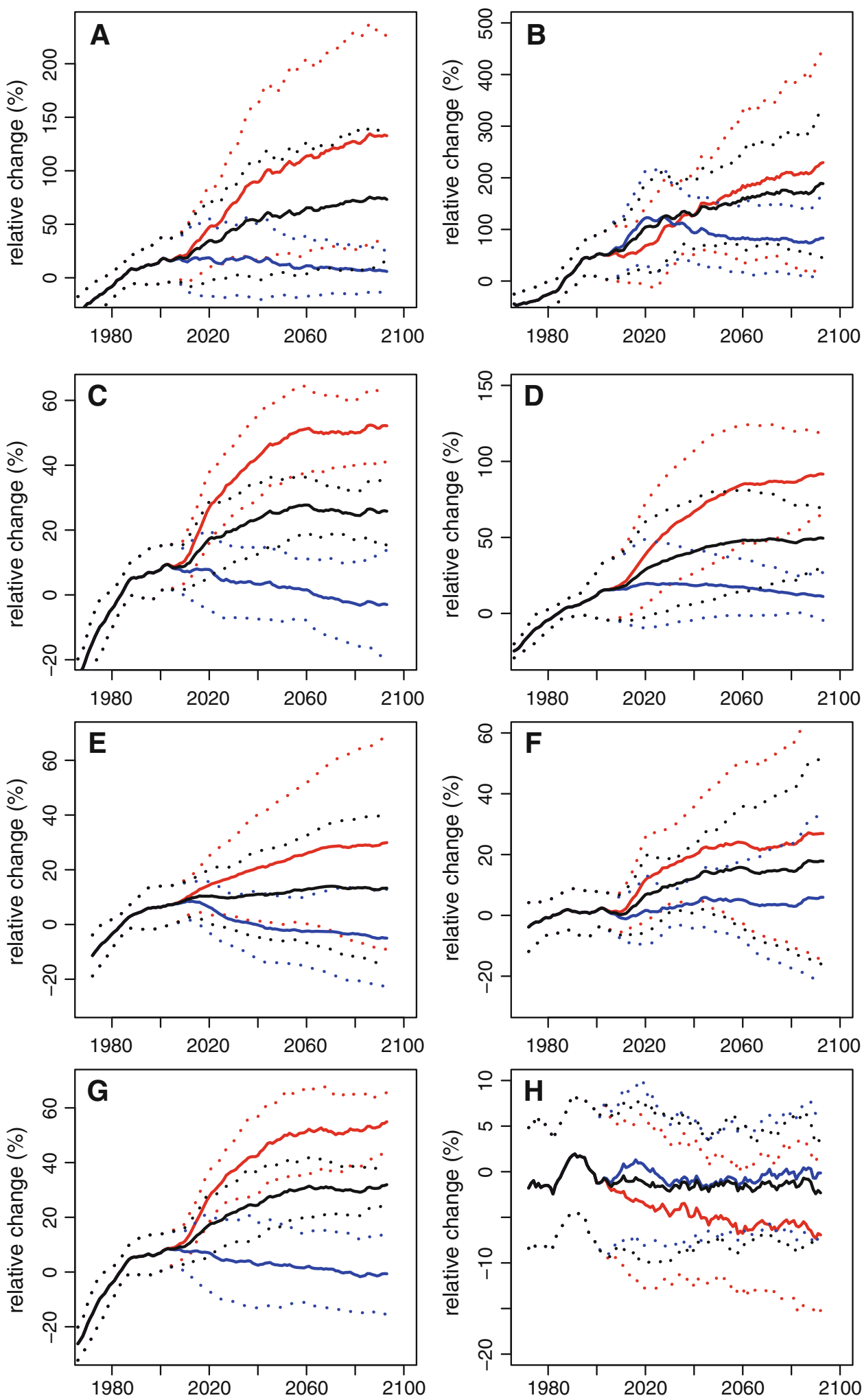

loads co-vary in all models and scenarios (Fig. 7, bottom left), but the DIN:DIP ratio in the nutrient supply is generally below the Redfield ratio. Excess phosphorus $(e \mathrm{DIP}=\mathrm{DIP}-\mathrm{DIN} / 16)$ in the supply from loads and bottom sediments (i.e., phosphorus fluxes not matched by nitrogen fluxes according to the Redfield ratio), weakly correlates with nitrogen fixation in all models and scenarios (Fig. 7, bottom right). The amount of nitrogen fixed is 
Fig. 6 Phosphorus (top) and nitrogen supply (bottom) to the water column of the Baltic Sea without Kattegat for the ensemble mean (middle) and the ensemble mean with \pm 1 standard deviations, calculated from six experiments (left and right). Dark gray, medium gray, and light gray shaded and solid bars show the nutrient output from the bottom sediments, input from nitrogen fixation, and net input from loads, exchange with the Kattegat and denitrification, respectively. CTL denotes fluxes during 1978-2007, BSAP, REF and BAU fluxes during 2069-2097 for the respective scenarios
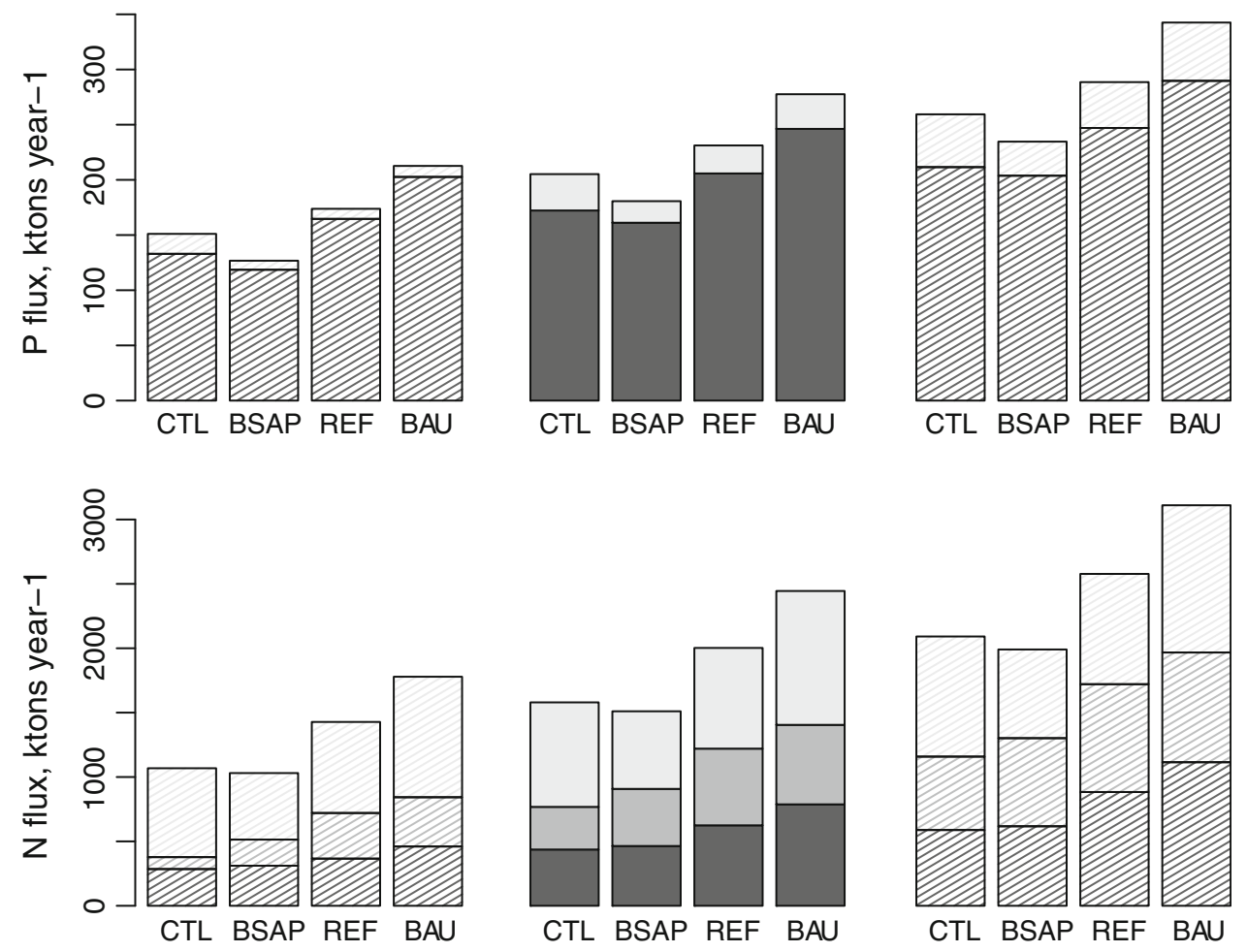
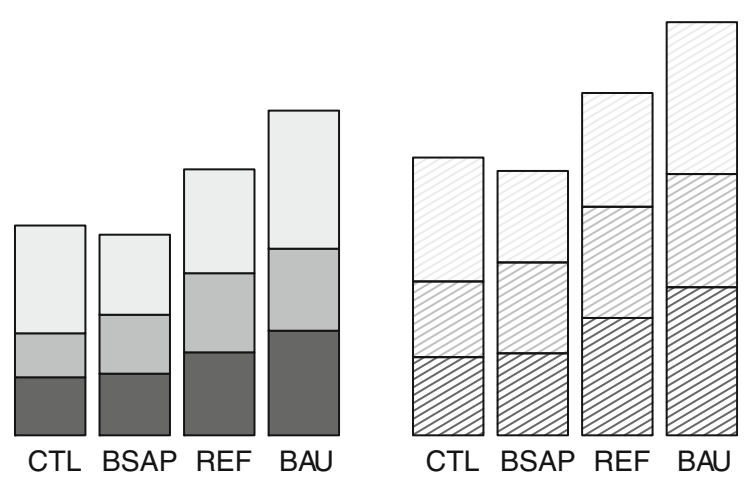

Table 1 Ensemble mean nutrient fluxes in present (CTL, 1978-2007) and future climate (2069-2097) for BSAP, REF, and BAU scenarios (entire Baltic Sea, excluding Kattegat) and standard deviation (in brackets)

\begin{tabular}{|c|c|c|c|c|c|}
\hline Flux & Units & CTL & BSAP & REF & BAU \\
\hline Primary production & $\mathrm{g} \mathrm{C} \mathrm{m}^{-2}$ year $^{-1}$ & $51.8(25.9)$ & $52.6(28.4)$ & $90.2(66.7)$ & $121.2(94.4)$ \\
\hline Nitrogen fixation & ktons $\mathrm{N}$ year $^{-1}$ & $331(239)$ & 444 (241) & $596(241)$ & $617(235)$ \\
\hline Loads (land + atm.), $\mathrm{N}$ & ktons $\mathrm{N}$ year $^{-1}$ & $835(111)$ & $604(73)$ & $819(54)$ & $1108(114)$ \\
\hline Loads (land + atm.), P & ktons $\mathrm{P}$ year $^{-1}$ & $39(13)$ & $27(7)$ & $39(11)$ & $51(15)$ \\
\hline Phytoplankton uptake, $\mathrm{N}$ & ktons $\mathrm{N}$ year $^{-1}$ & $3272(1594)$ & 3213 (1834) & $5662(4463)$ & 7792 (6317) \\
\hline Phytoplankton uptake, P & ktons $\mathrm{P}$ year $^{-1}$ & $507(257)$ & $515(282)$ & $884(661)$ & $1189(934)$ \\
\hline Sediment release, $\mathrm{N}$ & ktons $\mathrm{N}$ year $^{-1}$ & $437(152)$ & $464(153)$ & $625(259)$ & 788 (327) \\
\hline Sediment release, $\mathrm{P}$ & ktons $\mathrm{P}$ year ${ }^{-1}$ & $172(39)$ & $161(43)$ & $206(41)$ & $246(44)$ \\
\hline Denitrification & ktons $\mathrm{N}$ year $^{-1}$ & $1035(217)$ & 1002 (289) & $1294(257)$ & 1509 (296) \\
\hline Sediment burial, $\mathrm{N}$ & ktons $\mathrm{N}$ year $^{-1}$ & $83(62)$ & $60(47)$ & $97(70)$ & $159(120)$ \\
\hline Sediment burial, $\mathrm{P}$ & ktons $\mathrm{P}$ year ${ }^{-1}$ & $23(10)$ & $21(10)$ & $25(13)$ & $29(17)$ \\
\hline Net export, $\mathrm{N}$ & ktons $\mathrm{N}$ year $^{-1}$ & $23(62)$ & $1(64)$ & $37(68)$ & $69(82)$ \\
\hline Net export, $\mathrm{P}$ & ktons $\mathrm{P}$ year ${ }^{-1}$ & $6(9)$ & $7(8)$ & $13(10)$ & $19(12)$ \\
\hline Water column supply, $\mathrm{N}$ & ktons $\mathrm{N}$ year $^{-1}$ & $1580(356)$ & $1510(390)$ & $2003(451)$ & $2444(529)$ \\
\hline Water column supply, $\mathrm{P}$ & ktons $\mathrm{P}$ year ${ }^{-1}$ & $205(42)$ & $181(39)$ & $231(42)$ & $278(51)$ \\
\hline
\end{tabular}

generally larger than the Redfield equivalent of the excess phosphorus flux, because pelagic nutrient regeneration also plays an important role in sustaining nitrogen fixation at least in one of the three models. In addition, pelagic denitrification may add to the production of excess $\mathrm{P}$. However, the large scatter in the relationship suggests that other factors, in addition to the nutrient supply, play an important role in determining nitrogen fixation in the models. This finding is in agreement with other studies. Also, warm, calm, and sunny weather with high SSTs (above $15^{\circ} \mathrm{C}$ ) is a prerequisite for the growth of cyanobacteria. 

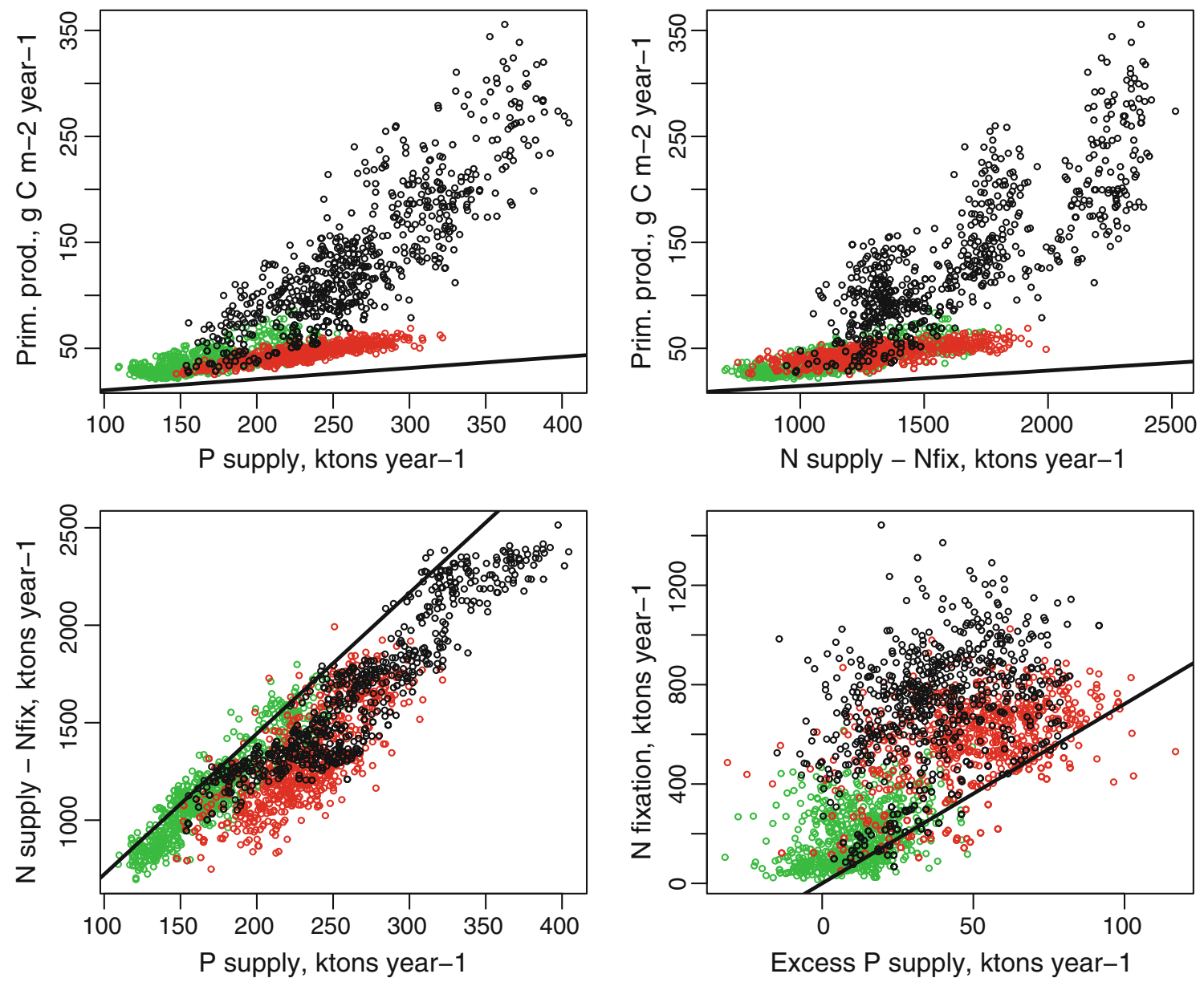

Fig. 7 Drivers of phytoplankton growth. Top panels Relationship between primary production and phosphorus (top left) and nitrogen (top right) supply to the water column given by release from the bottom sediments and net input from loads, exchange with the Kattegat and denitrification. Bottom panels The relationship between $\mathrm{N}$ and $\mathrm{P}$ supply (bottom left) and the relationship between nitrogen

\section{DISCUSSION}

\section{Reinforced "Vicious Circle"}

In this study, the combined impacts of climate change and various nutrient load scenarios on ecological quality indicators and biogeochemical fluxes in the Baltic Sea are investigated. The applied ensemble simulations suggest that changing internal phosphorus fluxes play a key role for future biogeochemical cycles in the Baltic Sea. A feedback mechanism is suggested that explains why changing climate counteracts nutrient load abatement strategies in our model experiments. Higher water temperatures reinforce the so-called vicious circle which was suggested by earlier studies (e.g., Vahtera et al. 2007; Savchuk 2010).

Higher water temperatures are projected to (1) reduce oxygen concentrations in the water column due to lower solubility of oxygen in warmer water and (2) accelerate

fixation and excess phosphorus calculated as $e$ DIP $=$ DIP - DIN/16 (bottom right). Dots Annual average fluxes for each ensemble member and cover the time period 1961-2097, with colors according to biogeochemical models (BALTSEM black, ERGOM green, RCOSCOBI red). Solid lines Relationships corresponding to Redfield ratios $(16 \mathrm{~mol} \mathrm{~N} / \mathrm{mol} \mathrm{P})$

organic matter mineralization and oxygen consumption. Greatly expanding anoxia will (3) increase phosphorus release rates from the sediments, and amplify the phosphorus recycling which will reduce the permanent removal of phosphorus from the ecosystem. Together with an accelerated pelagic recycling loop (4), this will intensify primary production. In addition, as the denitrification efficiency will decrease and nitrogen fixation increases, the pelagic nitrogen pool will increase as well. Finally, more nutrients in the water column will increase primary production and oxygen consumption, reinforcing the phosphorus release from the sediments.

The increased phosphorus mobility in hypoxic regions of the Baltic Sea affects also connected sub-basins. At least in two out of three ensemble members, phosphorus transports from the Baltic proper to adjacent seas are increased and phosphorus pools in the sediments of the Bothnian Sea will grow (not shown). As the phosphorus geochemistry in 
fresher water bodies is treated differently among the biogeochemical models, the response in the Bothnian Sea does not show an agreement. Lower denitrification efficiency in highly eutrophic and anoxic scenarios is a feature in two out of three biogeochemical models and determines the behavior of the ensemble average. Despite high denitrification rates, denitrification removes a smaller fraction of the nitrogen turnover and the growth of the pelagic DIN pool accelerates. This is in contrast to the state of the Baltic Sea during the 1980s and 1990s, when increasing hypoxia reduced the pelagic DIN pool (Vahtera et al. 2007; Savchuk 2010).

\section{Differences to Other Studies}

Meier et al. (2011b) studied the quasi-steady state response to changing climate in 100-year simulations. They found that in warmer waters, the spring bloom will start earlier but will also end earlier because nitrate concentrations limit biomass production. However, phytoplankton concentrations will decrease if increased wind-induced mixing causes a change in the DIN:DIP ratio. In the scenario simulations of this study, wind speed changes are relatively small and the latter effect is relatively unimportant.

Another reason for the different responses in this study and the study by Meier et al. (2011b) might be different parameterizations of temperature-dependent nutrient fluxes from the bottom sediments. In at least two out of three models of this study, the sensitivity of sediment nutrient remineralization to temperature changes is larger than in the model by Meier et al. (2011b), see Eilola et al. (2011). Hence, phytoplankton biomass changes caused by increased water temperatures are larger in this study than in the study by Meier et al. (2011b).

Neumann (2010) found that the season favoring cyanobacterial blooms is prolonged, with the spring bloom in the northern Baltic Sea beginning earlier in the season. However, there is little change in the annual nitrogen fixation. He further found that oxygen conditions in the deep water are expected to improve slightly, perhaps due to the decreasing stability of vertical stratification in the Gotland Sea, together with increased wind-induced mixing. Both the results contradict our findings. In the scenario simulations by Neumann (2010), the impact of increased water temperatures is very likely overshadowed by the impact of increased wind-induced mixing.

\section{CONCLUSIONS}

1. Ensemble modeling using a variety of models is a powerful tool to identify model biases, complementary to a comparison with scarce observations. Despite large uncertainties of simulated changes depending on the variable and region of interest, we found common ensemble mean changes of selected ecological quality indicators with signal-to-noise ratios larger than one.

2. Assuming present day REF nutrient loads, projections of selected ecological quality indicators suggest that in future climate, water quality will deteriorate. The results indicate that oxygen depletion in the bottom water, winter nutrient concentrations in the surface layer and phytoplankton concentrations in most areas of the Baltic proper will increase. Even in case of nutrient load reductions according to the BSAP and CLEG scenarios, the environmental situation will not improve significantly and in case of the BAU scenario, the water quality is considerably deteriorated compared to present conditions.

3. In warmer and more anoxic waters, increased phosphorus fluxes from the sediments will partly compensate the effects of the BSAP. Changes in both temperature (which directly affects phosphorus mineralization rates in the sediments) and oxygen conditions in the different nutrient load scenarios will accelerate the sediment phosphorus turnover.

4. Increased anoxia will reduce the denitrification efficiency. However, in the models, the internal phosphorus supply is the primary driver of primary production, which is mainly fueled by nitrogen and phosphorus release from the sediments, nitrogen fixation, and river loads.

Acknowledgments The research presented in this study is part of the project ECOSUPPORT (Advanced modeling tool for scenarios of the Baltic Sea ECOsystem to SUPPORT decision making) and has received funding from the European Community's Seventh Framework Program (FP/2007-2013) under Grant Agreement No. 217246 made with BONUS, the joint Baltic Sea research and development program, from the Swedish Environmental Protection Agency (SEPA, Ref. No. 08/381) and from the German Federal Ministry of Education and Research (Ref. No. 03F0492A). Additional support came from the Swedish Research Council for Environment, Agricultural Sciences and Spatial Planning (FORMAS) within the project "Regime Shifts in the Baltic Sea Ecosystem-Modeling Complex Adaptive Ecosystems and Governance Implications". The ERGOM simulations were performed on computers of the North German Supercomputing Alliance (HLRN). The RCOSCOBI model simulations were partly performed on the climate computing resources "Ekman" and "Vagn" that are operated by the National Supercomputer Centre (NSC) at Linköping University and the Centre for High Performance Computing (PDC) at the Royal Institute of Technology in Stockholm, respectively. These computing resources are funded by a grant from the Knut and Alice Wallenberg Foundation. We are in great debt to all institutes and individuals that kindly provided their data to the Baltic Environmental Database (BED) at the Baltic Nest Institute (http://nest.su.se/bed).

\section{REFERENCES}

Arheimer, B., J. Dahné, and C. Donnelly. 2012. How will climate change impact on riverine nutrient load and land-based measures 
of the Baltic Sea Action Plan? AMBIO. doi:10.1007/ s13280-012-0323-0.

BACC Author Team. 2008. Assessment of climate change for the Baltic Sea basin, 474. Berlin: Springer.

Conley, D.J., S. Björck, E. Bonsdorff, J. Carstensen, G. Destouni, B.G. Gustafsson, S. Hietanen, M. Kortekaas, et al. 2009. Hypoxia-related processes in the Baltic Sea. Critical Review. Environmental Science and Technology 43: 3412-3420.

Conley, D.J., J. Carstensen, J. Aigars, P. Axe, E. Bonsdorff, T. Eremina, B.-M. Haahti, C. Humborg, et al. 2011. Hypoxia is increasing in the coastal zone of the Baltic Sea. Environmental Science and Technology 45: 6777-6783.

Döscher, R., U. Willén, C. Jones, A. Rutgersson, H.E.M. Meier, U. Hansson, and L.P. Graham. 2002. The development of the regional coupled ocean-atmosphere model RCAO. Boreal Environmental Research 7: 183-192.

Eilola, K., H.E.M. Meier, and E. Almroth. 2009. On the dynamics of oxygen, phosphorus and cyanobacteria in the Baltic Sea; A model study. Journal of Marine Systems 75: 163-184.

Eilola, K., B.G. Gustafson, I. Kuznetsov, H.E.M. Meier, and O.P. Savchuk. 2011. Evaluation of biogeochemical cycles in an ensemble of three state-of-the-art numerical models of the Baltic Sea. Journal of Marine Systems 88: 267-284.

Elmgren, R. 2001. Understanding human impact on the Baltic Sea ecosystem: Changing views in recent decades. AMBIO 30: 222-231.

Fonselius, S., and J. Valderrama. 2003. One hundred years of hydrographic measurements in the Baltic Sea. Journal of Sea Research 49: 229-241.

Gordon, C., C. Cooper, C.A. Senior, H. Banks, J.M. Gregory, T.C. Johns, J.F.B. Mitchell, and R.A. Wood. 2000. The simulation of SST, sea ice extent and ocean heat transports in a version of the Hadley Centre coupled model without flux adjustments. Climate Dynamics 16: 147-166.

Graham, L.P. 2004. Climate change effects on river flow to the Baltic Sea. AMBIO 33: 235-241.

Gustafsson, B.G. 2003. A time-dependent coupled-basin model for the Baltic Sea, Report C47, Earth Sciences Centre, Göteborg University, Göteborg, $61 \mathrm{pp}$.

Gustafsson, B.G., and H.C. Andersson. 2001. Modeling the exchange of the Baltic Sea from the meridional atmospheric pressure difference across the North Sea. Journal of Geophysical Research 106: 19731-19744.

Gustafsson B.G., F. Schenk, T. Blenckner, K. Eilola, H.E.M. Meier, B. Müller-Karulis, T. Neumann, T. Ruoho-Airola, O.P. Savchuk, and E. Zorita. 2012. Reconstructing the development of Baltic Sea eutrophication 1850-2006. AMBIO. doi:10.1007/s13280012-0318-x.

HELCOM. 2007. Toward a Baltic Sea unaffected by eutrophication. Background document to Helcom Ministerial Meeting, Krakow, Poland, Tech. Rep., Helsinki Commission, Helsinki, Finland.

Jungclaus, J.H., M. Botzet, H. Haak, N. Keenlyside, J.J. Luo, M. Latif, J. Marotzke, U. Mikolajewicz, et al. 2006. Ocean circulation and tropical variability in the coupled ECHAM5/ MPI-OM. Journal of Climate 19: 3952-3972.

Kratzer, S., B. Håkansson, and C. Sahlin. 2003. Assessing Secchi and photic zone depth in the Baltic Sea from satellite data. AMBIO 32: $577-585$.

Leppäranta, M., and K. Myrberg. 2009. Physical oceanography of the Baltic Sea. Berlin: Springer. ISBN 978-3-540-79702-9.

Meier, H.E.M., R. Döscher, and T. Faxén. 2003. A multiprocessor coupled ice-ocean model for the Baltic Sea: Application to salt inflow. Journal of Geophysical Research 108: 3273. doi: 10.1029/2000JC000521.
Meier, H.E.M., H.C. Andersson, K. Eilola, B.G. Gustafsson, I. Kuznetsov, B. Müller-Karulis, T. Neumann, and O.P. Savchuk. 2011a. Hypoxia in future climates - a model ensemble study for the Baltic Sea. Geophysical Research Letters 38: L24608. doi: 10.1029/2011GL049929.

Meier, H.E.M., K. Eilola, and E. Almroth. 2011b. Climate-related changes in marine ecosystems simulated with a three-dimensional coupled biogeochemical-physical model of the Baltic Sea. Climate Research 48: 31-55.

Meier, H.E.M., A. Höglund, R. Döscher, H. Andersson, U. Löptien, and E. Kjellström. 2011c. Quality assessment of atmospheric surface fields over the Baltic Sea of an ensemble of regional climate model simulations with respect to ocean dynamics. Oceanologia 53: 193-227.

Meier, H.E.M., R. Hordoir, H.C. Andersson, C. Dieterich, K. Eilola, B.G. Gustafsson, A. Höglund, and S. Schimanke. 2012. Modeling the combined impact of changing climate and changing nutrient loads on the Baltic Sea environment in an ensemble of transient simulations for 1961-2099. Climate Dynamics. doi: 10.1007/s00382-012-1339-7.

Nakićenović, N., J. Alcamo, G. Davis, B. de Vries, J. Fenhann, S. Gaffin, K. Gregory, A. Grubler, et al. 2000. Emission scenarios. A special report of working group III of the intergovernmental panel on climate change, Cambridge University Press, 599 pp.

Neumann, T. 2010. Climate-change effects on the Baltic Sea ecosystem: A model study. Journal of Marine Systems 81: 213-224.

Neumann, T., W. Fennel, and C. Kremp. 2002. Experimental simulations with an ecosystem model of the Baltic Sea: A nutrient load reduction experiment. Global Biogeochemical Cycles 16: 1033.

Roeckner, E., R. Brokopf, M. Esch, M. Giorgetta, S. Hagemann, L. Kornblueh, E. Manzini, U. Schlese, et al. 2006. Sensitivity of simulated climate to horizontal and vertical resolution in the ECHAM5 atmosphere model. Journal of Climate 19: 3771-3791.

Samuelsson, P., C.G. Jones, U. Willén, A. Ullerstig, S. Golvik, U. Hansson, C. Jansson, E. Kjellström, et al. 2011. The Rossby centre regional climate model RCA3: Model description and performance. Tellus 63A: 4-23.

Savchuk, O.P. 2002. Nutrient biogeochemical cycles in the Gulf of Riga: Scaling up field studies with a mathematical model. Journal of Marine Systems 32: 235-280.

Savchuk, O.P. 2010. Large-scale dynamics of hypoxia in the Baltic Sea. In Chemical structure of pelagic redox interfaces: observation and modelling, ed. E.V. Yakushev. Handbook of environmental chemistry, 24 pp. Berlin: Springer. doi:10.1007/ 698_2010_53.

Savchuk, O.P., F. Wulff, S. Hille, C. Humborg, and F. Pollehne. 2008. The Baltic Sea a century ago-a reconstruction from model simulations, verified by observations. Journal of Marine Systems 74: 485-494.

Solomon, S., D. Qin, M. Manning, Z. Chen, M. Marquis, K.B. Averyt, M. Tignor, and H.L. Miller (eds.). 2007. Contribution of Working Group I to the Fourth Assessment Report of the Intergovernmental Panel on Climate Change. Cambridge: Cambridge University Press, $996 \mathrm{pp}$.

Stålnacke, P., A. Grimvall, K. Sundblad, and A. Tonderski. 1999. Estimation of riverine loads of nitrogen and phosphorus to the Baltic Sea 1970-1993. Environmental Monitoring and Assessment 58: 173-200.

Vahtera, E., D. Conley, B.G. Gustafsson, H. Kuosa, H. Pitkänen, O.P. Savchuk, T. Tamminen, M. Viitasalo, et al. 2007. Internal ecosystem feedbacks enhance nitrogen-fixing cyanobacteria blooms and complicate management in the Baltic Sea. AMBIO 36: $186-194$. 
Wulff, F., O.P. Savchuk, A.V. Sokolov, C. Humborg, and C.-M. Mörth. 2007. Management options and effects on a marine ecosystem: Assessing the future of the Baltic Sea. AMBIO 36: 243-249.

\section{AUTHOR BIOGRAPHIES}

H. E. Markus Meier $(\square)$ is an adjunct professor at Stockholm University and head of the Oceanographic Research Unit at the Swedish Meteorological and Hydrological Institute (SMHI). His current research interests focus on the analysis of climate variability and the impact of climate change on the physics and biogeochemical cycles in the Baltic Sea, North Sea, and Arctic Ocean.

Address: Swedish Meteorological and Hydrological Institute, 60176 Norrköping, Sweden.

e-mail: markus.meier@smhi.se

Bärbel Müller-Karulis is a guest researcher at the Baltic Nest Institute, Stockholm University. She has worked with Baltic ecosystem status assessment and biogeochemical modeling at the Latvian Institute of Aquatic Ecology since 1997. In 2010, she earned a PhD from the University of Latvia with focus on biogeochemical modeling.

Address: Baltic Nest Institute, Stockholm University, 10691 Stockholm, Sweden.

e-mail: Baerbel.muller-karulis@stockholmresilience.su.se

Helén C. Andersson is a researcher and research coordinator at the Swedish Meteorological and Hydrological Institute. She is interested in physical and biogeochemical dynamics of the sea, with special emphasis on water quality and impact of climate variability.

Address: Swedish Meteorological and Hydrological Institute, 60176 Norrköping, Sweden.

e-mail: helen.andersson@smhi.se

Christian Dieterich is an oceanographer at the SMHI. His research interests include natural climate variability, its impact on ecosystems, ocean dynamics, and numerical modeling.

Address: Swedish Meteorological and Hydrological Institute, 60176

Norrköping, Sweden.

e-mail: christian.dieterich@smhi.se

Kari Eilola is an oceanographer and senior scientist at the department of research and development at the Swedish Meteorological and Hydrological Institute (SMHI). His research interests include physical and biogeochemical modeling of the Baltic Sea.

Address: Swedish Meteorological and Hydrological Institute, 42671

Västra Frölunda, Sweden.

e-mail: kari.eilola@smhi.se

Bo G. Gustafsson is an associate professor in physical oceanography and presently works as managing director of the Baltic Nest Institute, Stockholm University. The main research focus being modeling of the Baltic Sea region, in particular problems related to eutrophication. Address: Baltic Nest Institute, Stockholm University, 10691 Stockholm, Sweden.

e-mail: bo.gustafsson@stockholmresilience.su.se
Anders Höglund has a Ph.D. in mathematics from Linköping University and is currently working as researcher in oceanography at SMHI. Current research interest includes current patterns in the Baltic Sea.

Address: Swedish Meteorological and Hydrological Institute, 60176

Norrköping, Sweden.

e-mail: anders.hoglund@smhi.se

Robinson Hordoir is a physical oceanographer specialized in numerical model development and analysis of ocean processes. His interest focus on Baltic and North Sea dynamics, as well as processes related with regions of freshwater influence and their coupling with river inflows.

Address: Swedish Meteorological and Hydrological Institute, 60176 Norrköping, Sweden.

e-mail: robinson.hordoir@smhi.se

Ivan Kuznetsov is working at the oceanographic research group at the Swedish Meteorological and Hydrological Institute (SMHI). His research interests include numerical modeling of the Baltic Sea ecosystem.

Address: Swedish Meteorological and Hydrological Institute, 60176 Norrköping, Sweden.

e-mail: ivan.kuznetsov@smhi.se

Thomas Neumann is a senior scientist working in the department of physical oceanography in the Baltic Sea Research Institute (IOW). After an initial oceanographic career in small-scale processes in the sea he turned his scientific interest in the 1990s to coupled physical and biogeochemical modeling.

Address: Leibniz-Institute for Baltic Sea Research Warnemünde, Seestr. 15, 18119 Rostock, Germany.

e-mail: Thomas.Neumann@io-warnemuende.de

Zohreh Ranjbar has a PhD in scientific computing from Linköping University and is currently working as a researcher in oceanography at SMHI. Her current research includes the impact of climate change on the physics and biogeochemical cycles in the Baltic Sea.

Address: Swedish Meteorological and Hydrological Institute, 60176 Norrköping, Sweden.

e-mail: zohreh.ranjbar@smhi.se

Oleg P. Savchuk graduated from the Leningrad State University (USSR) in 1971 as oceanographer. Since then he uses mathematical modeling as a tool to study marine ecosystems of the Baltic, North, White, and Barents seas with emphasis on nutrient biogeochemical cycles.

Address: Baltic Nest Institute, Stockholm University, 10691 Stockholm, Sweden.

e-mail: oleg@mbox.su.se

Semjon Schimanke has a PhD in meteorology from the Freie Universität Berlin and is currently working as a researcher in oceanography at SMHI. His current research interests are the climate of the past, natural climate variability, and climate modeling.

Address: Swedish Meteorological and Hydrological Institute, 60176 Norrköping, Sweden.

e-mail: semjon.schimanke@smhi.se 